\title{
CIDADE MARAVILHOSA: EXPLORAÇÃO DOS SENTIDOS DE UMA METONÍMIA
}

\author{
Cidade Maravilhosa: exploration of the meanings of a metonymy
}

Priscilla Xavier (IPPUR/UFRJ)

\begin{abstract}
RESUMO: O presente artigo propõe uma possibilidade de compreensão da dinâmica do dizer a cidade. Considerando o dizer um fenômeno social, pretendemos exercitar uma análise de discurso, que toma o termo "Cidade Maravilhosa" como uma metonímia do Rio de Janeiro, admitindo em tal dizer um teor dinâmico. Buscamos apreender a dinâmica da "Cidade Maravilhosa" a partir de uma analogia ao caleidoscópio, produzindo imagens de conjunturas, organizando e expondo conteúdos relevantes e eloquentes para compreensão dos sentidos dos discursos. Nesse caleidoscópio três superfícies espelhadas refletem objetos que, em movimento, produzem imagens sucessivas, entre possibilidades de combinações inúmeras. A política, a cultura e o urbanismo serão os espelhos e as narrativas acerca da Cidade Maravilhosa os objetos em movimento que serão refletidos. A imagem do Rio de Janeiro será composta por conjunturas institucionais distintas, sejam elas o Rio de Janeiro como capital da república, Estado da Guanabara e Rio de Janeiro pós-fusão. O resultado é a percepção da mudança dos conteúdos que conferem sentido aos discursos sobre o Rio de Janeiro, no que tange o imaginário e as disputas de poder expressas ou inspiradas na Cidade Maravilhosa.
\end{abstract}

PALAVRAS-CHAVE: Discurso; Cidade; Memória; Imaginário; Política.

ABSTRACT: This article proposes a possibility of understanding the dynamics of saying about the city. Considering the saying as a social phenomenon, we do an exercise of a discourse analysis, which takes the term "Cidade Maravilhosa" as a metonymy of Rio de Janeiro, admitting a dynamic content. We intends to apprehend the dynamics of the "Cidade Maravilhosa" using an analogy to kaleidoscope, producing images of conjunctures, organizing and exposing relevant and eloquent contents for understanding the meanings of discourses. In this kaleidoscope three mirrored surfaces reflect objects that produce successive images, among possibilities of numerous combinations. Politics, culture and urbanism will be the mirrors and the narratives about the "Cidade Maravilhosa" will be the moving objects reflected. The image of Rio de Janeiro will be composed of distinct institutional conjunctures: Rio de Janeiro as the capital of the republic, the State of Guanabara and Rio de Janeiro post-merger. The result is the perception of the changing of contents that give meaning to the discourses about Rio de Janeiro, expressed or inspired by "Cidade Maravilhosa".

KEYWORDS: Discourse; City; Memory; Imaginary; Policy. 


\section{Introduction}

O Rio de Janeiro figura entre as grandes cidades da economia mundial. Seu posicionamento destacável no país e no mundo, longe de um fenômeno que ocorreu da noite para o dia, corresponde a um longo processo histórico, constituído por tramas políticas, econômicas, sociais e culturais. Desde a virada do século XIX para o século XX o Rio de Janeiro sintomatiza de modo exemplar mudanças paradigmáticas deflagradas pelos novos processos de acumulação, sensibilidades e modos de compreender o mundo. E como capital do Brasil, a cidade foi apropriada tanto para as funções administrativas quanto às subjetivas, sobretudo na proliferação de discursos em torno de ideais de nação, do progresso e da modernidade. Em tal configuração eruptiva de discursos sobre a cidade buscamos as primeiras aparições do termo "Cidade Maravilhosa" para representar o Rio de Janeiro. Exercitando uma Análise de Discurso, abordamos as primeiras aparições e perseguimos nas distintas fases institucionais os modos como o termo fora apropriado, os objetivos que animaram a apropriação e os significados possíveis dos discursos inspirados no termo.

Investimos na Análise do Discurso como saber e prática devotados à compreensão da linguagem como resultado de um processo histórico. Consideramos que o desenvolvimento do campo parte da "confluência entre a linguística e as ciências sociais" (ORLANDI, 2007, p.16). E com uma breve explanação sobre a Análise de Discurso, situamos a proposta de compreensão da dinâmica do dizer a cidade como um fenômeno social, na medida das interfaces teórico-metodológicas entre a linguística, a sociologia e a antropologia.

Provoca a nossa análise a metonímia de dizer "Cidade Maravilhosa" para se referir à cidade do "Rio de Janeiro". Pondo tal fenômeno em análise, pretendemos compor uma leitura densa dos modos de dizer o Rio de Janeiro pela Cidade Maravilhosa. $\mathrm{Ou}$, em outros termos, empregamos a Análise do Discurso para descolar o dizer Cidade Maravilhosa do senso comum. Tomamos como base conceitos e ideias consagradas pela Análise de Discurso Francesa[1], depurando os sentidos dos discursos derivados da Cidade Maravilhosa em relação a conjunturas institucionais da cidade do Rio de Janeiro, moldando as orientações às especificidades da nossa reflexão.

Buscamos a origem do termo "Cidade Maravilhosa" no contexto das reformas urbanas promovidas por Pereira Passos, sugerindo a consolidação do termo como artifício para a legitimidade da república e elogio à modernidade. Passamos para o emprego estratégico da Cidade Maravilhosa no período da Guanabara, destacando a 
reversão de um quadro político desfavorável e reação à uma crise identitária. E encerramos com o atual emprego do dizer Cidade Maravilhosa como marca para promover o Rio de Janeiro, tal e qual uma cidade-mercadoria, local para consumir e mercadoria a ser consumida, em uma conjuntura de competitividade entre cidades globais.

Estimula a nossa reflexão a ideia de que o ato de dizer a cidade tem relevância e sentidos que extrapolam a definição literal, que superam a descrição denotativa dos aspectos geográficos ou equipamentos urbanos para definir a cidade. E que o dizer "Cidade Maravilhosa" atravessa o século como o dizer sobre o Rio de Janeiro, expressando e inspirando significados bastante diversos conforme a conjuntura.

Para nos aproximarmos da perspectiva de uma dinâmica do dizer Cidade Maravilhosa tomamos como referência as experiências para a compreensão da cidade contemporânea[2], adaptando a analogia ao caleidoscópio. O instrumento ótico nos favorece a ideia de composição de quadros/imagens efêmeras, dado por um efeito de justaposição de espelho e movimento de objetos. No caleidoscópio três superfícies espelhadas refletem objetos que, em movimento, produzem imagens sucessivas, entre possibilidades de combinações inúmeras. Em nosso exercício simulamos o caleidoscópio ao consideraremos a política, a cultura e o urbanismo como os espelhos, e os objetos em movimento que serão refletidos os discursos derivados de "Cidade Maravilhosa".

À guisa de organização, introduzimos uma apreensão da análise de discurso que se desdobrará no exercício de leitura que pretendemos. Em seguida, abordamos as narrativas acerca da Cidade Maravilhosa em cada uma das três imagens institucionais do Rio de Janeiro: capital da república, Estado da Guanabara e Rio de Janeiro pós-fusão. Em cada qual descrevemos uma composição informada pela ordem econômica, política, histórica e cultural, destacando a encenação do poder na produção do espaço urbano. E a partir de tais composições tentamos decantar os sentidos dos discursos, esboçando o imaginário atuante e as disputas de poder expressas ou inspiradas em "Cidade Maravilhosa".

\section{Da Análise de Discurso}

Antes de tratarmos do Rio de Janeiro como Cidade Maravilhosa, cumpre afinarmos a Análise de Discurso como ferramenta de leitura e interpretação da sociedade, para melhor explicitar a produção de sentidos. Tomamos como ponto de 
partida as contribuições de Pêcheux (2009; 2011), sem contudo compor uma abordagem robusta, que dê conta do volume, profundidade e complexidade de sua produção, tampouco do movimento conhecido como Análise de Discurso de linha francesa. Nos pautamos mais concisamente pela necessidade de dar nitidez aos estímulos para a constituição da Análise de Discurso, tentando delinear os possíveis elementos, conceitos e ideias, articulados em nosso exercício de reflexão.

Ao tomar nossa proposta de exercitar a leitura de discursos a partir de conjunturas, seria uma falta grave remontarmos o surgimento da Análise de Discurso como um saber/prática sem mencionarmos as questões políticas, econômicas, sociais e culturais que animavam o período. E alguns dos estímulos associados ao surgimento da Análise do Discurso se concentram na década de 1960. Entre as inúmeras perspectivas que poderiam ser acionadas para descrever o período, nos convém à melhor compreensão do surgimento da Análise de Discurso a da proliferação na Europa de projetos culturais e ideológicos alternativos, deflagrados pela ascensão de movimentos civis, investimentos simbólicos e, de modo amplo, mas não exatamente generalista, de posicionamentos integrados ou questionadores de um tipo de modernidade, refletindo sobre suas promessas e limites. Em tal configuração a Análise de Discurso pode ser sugerida como uma das consequências da tomada de consciência política do período, tensionando o campo da linguística.

Produzindo estudos da linguagem pautados em um estruturalismo hermético, a linguística até a década de 1960 apreendia a linguagem encerrada em suas regras. E sobre tal formalismo passaram a incidir críticas quanto a negação das exterioridades, uma vez que na linguagem eram ignorados os atravessamentos das dinâmicas sociais, psíquicas, culturais, políticas e econômicas.

Captando o desafio de produzir estudos sobre a linguagem abarcando as exterioridades, a Análise do Discurso se desenvolve como um campo. Em uma formulação imprecisa, se abria à confluência de saberes para assumir o teor simbólico e a divisão política dos sentidos na linguagem. Em tal processo os estudos da linguagem não abandonam por completo o estruturalismo, mas adotaram como corte epistemológico a mudança de compreensão da linguagem. Antes como objeto natural, a linguagem passa então a ser compreendida como objeto social. E fazendo uma ponte entre a linguística e as ciências sociais, a Análise de Discurso incorpora e adapta aos estudos da linguagem a dimensão psíquica e o materialismo histórico. 
Compondo um quadro das referências para a constituição do novo campo, saber/prática, em Seman̂tica e discurso, Michel Pêcheux (2009) apresenta e complexifica um conjunto de orientações relativos à Análise de Discurso, ressaltando na produção e usos da linguagem a ideologia e a psique. Sobre a ideologia se inspira em Althusser, sobretudo na concepção dos Aparelhos Ideológicos do Estado como peão na luta de classes, pautando que "a ideologia da classe dominante não se transforma em ideologia dominante pela graça de Deus..." (ALTHUSSER, 1971, p.185 apud CARNOY; 1988, p.123). Justamente na instauração dos aparelhos Ideológicos é que a ideologia é realizada e se realiza, reproduzindo as relações de produção e, simultânea e contraditoriamente, carregando as possibilidades de reversão do quadro. E explorando o inconsciente, a Análise de Discurso se inspira nos trabalhos de Lacan, na articulacão de que o conteúdo é ocultado pela forma. É válido sinalizar que a contribuição da psicanálise se coaduna com o materialismo histórico, pela ideia do fascínio fetichista que, grosso modo, pode ser ilustrado pelo efeito de perverter relações sociais em relações econômicas.

Avançando pela dimensão do poder, no artigo A seman̂tica e o corte saussuriano: lingua, linguagem e discurso, Pêcheux tratou da formação discursiva, advertindo que "O elo que liga as significações de um texto às suas condições sócio-históricas, não é secundário, mas constitutivo das próprias significações" (Pêcheux, 1971, p.147). E Michel Foucault operou o que chamou de método arqueológico, tratando das condições de possibilidade da formação de enunciados científicos, identificando na formação de enunciados em determinados períodos históricos a "vontade de verdade". Os autores, por assim dizer, se aproximaram ao produzir conceitos e métodos entre a filosofia e a história, no intuito de refletir e produzir compreensões sobre as formas discursivas relacionadas com a ideia de poder. Todavia, cada qual desenvolveu a contribuição à Análise de Discurso de um modo.

No caso de Michel Foucault, a Análise do Discurso em uma concepção arqueológica acabou sendo disseminada meramente como uma análise histórica. Tal compreensão é em alguma medida o preço da popularização dos escritos do autor, que se reflete inclusive na identificação do filósofo Michel Foucault como um historiador. Sem enxergar na popularidade um demérito, destacamos a necessidade de uma apreensão um tanto mais crítica do campo em que o trabalho se insere e dos diálogos que propõe. Não se trata de acusar um erro absurdo a identificação do trabalho como uma análise histórica, mas de qualificar a proposta. E Foucault se distingue da análise histórica por evitar a busca de uma repetição, de uma origem ou interpretação de algo 
"dito". Tanto se distingue que até encaminha críticas à história como disciplina ou saber institucionalizado. O que Foucault enfatiza mais especificamente é a necessidade de considerar as condições históricas para o aparecimento de um discurso que se pretende verdade, conduzindo uma história crítica do saber, do poder e das subjetividades.

Assim como as abordagens de Foucault se confundem com análises históricas, a Análise de Discurso por vezes é tomada como uma análise linguística contextualizada, ligando as práticas de produção discursiva às práticas políticas. A apreensão é razoável, mas peca em alguns aspectos, como o de homogeneizar enfoques possíveis da Análise de Discurso apropriada e desenvolvida em períodos, lugares e campos de saberes diversos. Clarificando nossa proposta, tratamos das condições sociais de produção dos discursos, em uma análise mais descritiva que explicativa, buscando avaliar as estratégias políticas e eficácia dos processos comunicativos, interpretando conteúdos. Sem negar a ideologia, pretendemos dar mais destaque para a dinâmica e as disputadas em torno da produção de sentidos.

Analisando a metonínimia Cidade Maravilhosa, e os discursos nela inspirados, ao longo das fases institucionais do Rio de Janeiro, produzimos uma montagem que se assemelha com uma análise histórica, pela noção de reconstrução de contexto. No entanto, asseveramos o teor crítico, dando conta das nuances dos sentidos conferidos aos discursos. Lidamos com a perspectiva de Foucault de que as coisas que o signo designam não se limitam à língua. Nas palavras do filósofo: “Certamente os discursos são feitos de signos; mas o que fazem é mais que utilizar esses signos para designar coisas. É esse mais que os torna irredutiveis à língua e o ato de quem fala. É esse mais que é preciso fazer aparecer e que é preciso descrever" (FOUCAULT, 1997, p. 56).

\section{Rio de Janeiro, Distrito Federal}

Disposta a estrutura teórica que inspira a nossa leitura crítica - a Análise de Discurso -, passamos a falar do Rio de Janeiro. Construímos imagens caleidoscópicas sobre o Rio de Janeiro por uma espécie de colagem, unindo elementos da política, cultura, economia e do desenvolvimento urbano, compondo o que pode ser sugerido como uma conjuntura, dada pela figura institucional da cidade. Nas conjunturas identificamos os discursos como instrumentos de poder, como artifício político, intrínsecos à produção e às dinâmicas do espaço urbano, em alguma medida condicionado pelas relações sociais. Discorremos sobre a produção do espaço urbano 
como um processo, sem forma acabada ou estática, entendendo o espaço como o lugar de práticas. Com a contribuição de Georges Balandier (1982) inclinamos o processo de produção do espaço à encenação do poder. Observamos a inscrição do poder nas cenas construídas nos espaços, por sucessivos regimes, abundantes em símbolos e significações, conferindo sentido para a realidade através do imaginário, como artifício para sustentar o poder. Nas palavras de Georges Balandier:

O poder estabelecido unicamente sobre a força ou sobre a violência não controlada teria uma existência constantemente ameaçada; o poder exposto debaixo da iluminação exclusiva da razão teria pouca credibilidade. Ele não consegue manter-se nem pelo domínio brutal e nem pela justificação racional. Ele só se realiza e se conserva pela transposição, pela produção de imagens, pela manipulação de símbolos e sua organização em um quadro cerimonial. Estas operações se efetuam de modos variáveis, combináveis, de apresentação da sociedade e de legitimação das posições do governo (BALANDIER, 1982, p.7).

Iniciamos as imagens do Rio de Janeiro com a figura institucional de capital da república. Na primeira imagem caleidoscópica o Rio de Janeiro tem como cor mais viva a narrativa de um novo sistema, dando brilho ao nacionalismo e à modernidade. A tal ponto que falar do Rio de Janeiro, a capital da república, é falar de Brasil. Pesamos na conjuntura o fato de que a mudança do regime monárquico para o republicano ocorreu sem que houvesse um preparo, uma narrativa, uma encenação capaz de dar suporte à introdução do novo sistema, de modo a torná-lo significativo para o coletivo. E na tentativa de preencher tal ausência, um plano urbanístico na capital veio a calhar como medida e expressão, alavancando uma ordem racional, moderna e civilizada.

Como capital da república, no Rio de Janeiro, a narrativa do nacional foi tão vultuosa que não seria exagero dizer que anestesiou a existência/referência local. E o discurso republicano aconteceu na cidade especialmente com a atuação de Pereira Passos e o auxílio de Oswaldo Cruz, o primeiro tratando das formas para o embelezamento, tomando como modelo acabado Paris, e o segundo disciplinando os corpos, tratando do saneamento. Ambos, chancelados pelo poder público, impuseram novos ideais, dando conteúdo a um imaginário urbano moderno e civilizado. Tal imaginário se torna a chave para a compreensão das narrativas do período sobre as cidades em geral e sobre o Rio de Janeiro, capital federal, especificamente.

Sem abandonar a dimensão territorial e política, avançamos para a perspectiva linguística, pretendendo dar visibilidade para o emprego estratégico da linguagem como instrumento para o exercício do poder. E lançamos mão da contribuição de Michel 
Foucault, cujas reflexões escoam para a perspectiva de que o discurso é a base de um conceito deveras importante e amplamente utilizado por teóricos que se ocupam das relações de poder: a governamentalidade. Para Foucault, governar é "estruturar o eventual campo de ação dos outros" (1995, p. 244).

Vasculhando o contexto das primeiras intervenções urbanas na república em busca da origem do termo "Cidade Maravilhosa" para se referir ao Rio de Janeiro, alcançamos ao menos duas possibilidades de autoria. Uma delas a da poetisa francesa Jeane Catulle e a outra a do escritor pernambucano Coelho Neto. Em O Rio de todos os Brasis: uma reflexão em busca da auto-estima[3], Carlos Lessa, logo na introdução, afirma:

O Rio como projeto e sonho foi, na virada do século, a condensação do Progresso, tendo na largura das avenidas, na opulência dos bulevares, no faiscar da iluminação noturna e no circular elegante pela Avenida Central uma comprovação inequívoca. A população, nas calçadas, teria a demonstração concreta da modernidade do brasileiro. A República fez do Rio o espelho da nação como futuro feito presente. Esta foi uma operação extremamente bem sucedida: o Rio como cartão de visitas do país e certidão de brasilidade, como lugar único que combinava a natureza tropical com a modernidade urbana, foi batizado Ville Merveilleuse pela francesa Jeanne Catulle Mendes, em 1912 (LESSA, 2000, p.13).

Segundo o autor, em 1912 a francesa Jane Catulle batizou o Rio de Janeiro ao dar o título de Ville Merveilleuse à sua coletânea de poemas sobre a cidade. A visita de Jeane Catulle ao Rio de Janeiro, de setembro a dezembro de 1911, coincide com período em que as reformas promovidas por Pereira Passos cintilavam, arrancando suspiros dos estrangeiros e enchendo de orgulho a sociedade carioca.

A poetisa francesa desembarcou no Rio de Janeiro para participar de três conferências, uma delas no Teatro Municipal. E como figura de bons contatos e prestígio, esteve presente até mesmo em uma audiência com o então presidente da República, Washington Luis P. de Sousa. Com uma estadia de pompa e interlocutores ávidos por suas impressões sobre a cidade, a autora escreve poemas decantando o deslumbramento de sua visita, como é notável em um trecho de Arrivée dans la baie de Guanabara (MENDÈS,1913):

Jamais tant de splendeurs n'ont ébloui les yeux !

$C^{\prime}$ est ici le pays de toute la lumière,

C'est ici le pays de la beauté plénière,

Des terrestres beautés et des beautés des cieux ${ }^{[4]}$ 
Apesar do enorme prestígio da poetisa e de sua gentil obra inspirada no Rio de Janeiro, seria precipitado conferir à Jane Catulle a autoria do termo Cidade Maravilhosa para falar do Rio de Janeiro. Em um levantamento em dois grandes periódicos da época, A Notícia e O Paiz, verificamos ocorrências do termo em datas anteriores à visita da poetisa, deixando no ar a sugestão de que a autora estava afinada ao que era dito sobre cidades e até certo ponto com o que era dito sobre o Rio de Janeiro.

Na busca do termo "Cidade Maravilhosa", entre os anos de 1900 e 1910, tivemos nove ocorrências. Tendo em conta que na cidade os letrados não eram maioria, que havia um sem número de publicações de pequenas tiragens e que a literatura era mais difundida que propriamente a mídia, as ocorrências não dizem sobre a frequência do termo, mas evidenciam a existência e deixam investigar seu uso.

Nas primeiras ocorrências, no Jornal A Notícia, temos a Cidade Maravilhosa como um termo aplicável a qualquer cidade, uma delas em um texto de ficção. Nos chamou atenção o fato de que em uma outra ocorrência do termo, encontrada na coluna "Registro", o autor faz entusiasmantes elogios ao progresso e à paisagem urbana, jardins, edifícios e boulevards. No entanto, a Cidade Maravilhosa a que se refere é Paris. E o mesmo autor, no mesmo periódico e na mesma coluna, em outra data escreve um texto novamente exaltando Paris como Cidade Maravilhosa.

A primeira aparição constando o termo cidade maravilhosa relacionado ao Rio de Janeiro em "A notícia" é em uma coluna intitulada "Dez annos atrás", em 1909. No entanto, cumpre relatar que está indisponível para consulta as edições de A Notícia no ano de 1908. E há referências que assinalam o período de 1908 como o do surgimento do termo, nas crônicas de Coelho Neto[5]. E já bem próximo da visita de Jane Catulle, temos mais uma referência da Cidade Maravilhosa, em 1910, no texto intitulado A Cidade (A Notícia, Rio de Janeiro, p.1, 15 ago. 1910):

E por um dia assim que a cidade melhor brilha nas suas pompas e galas, ostentando os esplendores de uma cidade maravilhosa, feita de flores e revérberos, deitada numa infinita preguiça, á borda do grande golfo, à sombra de suas florestas onde chalram aves aos milhares.

Em O Paiz a Cidade Maravilhosa também aparece inicialmente distante do Rio de Janeiro, no texto "Paris e a exposição" (O Paiz, Rio de Janeiro, 9 fev. 1900, p.2). Mas logo em 1904 está registrado em versos irreverentes, que com métrica e rima chafurdam no conteúdo que perscrutamos do imaginário do Rio de Janeiro como cidade moderna, 
em "Matriculados e não Matriculados". Trata-se de uma troça à repressão municipal nas ruas em meio ao carnaval.

\author{
Essa gaiola bonita \\ Que vai ahi sem embaraços \\ É a invenção mais catita \\ Do genial Dr. Pereira Passos \\ As ruas de ponta a ponta \\ Subindo e descendo morros, \\ Por onde passa dá conta \\ Dos vagabundos cachorros. \\ Agarra! Cerca! Segura! \\ - Grita a matilha dos guardas - \\ Correndo como em loucura \\ Com um rumor de cem bombardas. \\ Terra sempre em polvorosa \\ Bem igual no mundo inteiro, \\ Cidade maravilhosa! \\ Salve, Rio de Janeiro! \\ (O Paiz, Rio de Janeiro, 16 fev. 1904, p.2)
}

No mesmo ano, meses depois, temos uma ocorrência que dá conta da transformação do urbano, em um enorme esforço de melhoramentos para o desenvolvimento das forças econômicas e do progresso do Brasil, nas promessas alinhadas na inauguração do governo de Rodrigues Alves, no texto intitulado "Uma obra política" (O Paiz, Rio de Janeiro, 4 Maio, 1904, p.1).

Em abril de 1905 o termo aparece na coluna "O Dia”, assinada por Pangloss. Entre outras coisas, Pangloss explica que vindo de São Paulo, estando oito anos ausente, tinha que falar dessa cidade maravilhosa. A cidade maravilhosa é São Paulo. Também desvinculado ao Rio de Janeiro, o termo aparece em 1907, na coluna "Lucta Romana", rendendo homenagens a Raoul Le Boucher. A cidade maravilhosa éSourgues, na França, onde o lutador nasceu. O termo volta a aparecer relacionado ao Rio de Janeiro no ano de 1908, em agosto e novembro, para relatar como a cidade estava preparada para receber uma exposição nacional.

Organizando as ocorrências, temos a "Cidade Maravilhosa" até 1904 aparecendo como referência a cidades reais e fictícias. Em 1904 aparece uma primeira referência relacionada ao Rio de Janeiro, em O Paiz, e em 1909 em A Notícia. Em ambos os casos a referência dialoga com as reformas de Pereira Passos, embebidas no imaginário da 
cidade moderna. E a despeito das ocorrências relacionadas ao Rio de Janeiro, o termo volta a aparecer para tratar de outras cidades, reais e fictícias.

Preenchendo a lacuna de 1908, do Jornal A Notícia, abordamos a referência de Coelho Neto, mais especificamente o texto apontado como o que dá origem ao termo "Cidade Maravilhosa". Uma possível compreensão da crônica de Coelho Neto está baseada na dualidade entre a real cidade do interior e a cidade do sonho. Conta a história de Adriana, uma professora interiorana, que, quebrando a monotonia do lugar e a falta de perspectivas, é seduzida por um pintor que faz uma estadia em seu povoado, vindo do Rio de Janeiro. Em uma noite de paquera o conto incita o imaginário de Adriana apontando para um fogaréu verbalizando "a Cidade Maravilhosa". Em abono da verdade, o local apontado era um elemento para simbolizar a Cidade Maravilhosa, que jamais foi literalmente identificada como sendo o Rio de Janeiro. O caso é que a cidade do Rio de Janeiro foi sendo referida como maravilhosa por um deslize na compreensão, um embaralhamento[6] da narrativa.

Em suma, da busca pela origem do termo Cidade Maravilhosa em expressões das letras no período institucional do Rio de Janeiro como capital da república, podemos fazer algumas pontuações. Primeiramente, não há como dedicar à Jeane Catulle a autoria do termo. Antes da visita da poetisa o termo já figurava nos periódicos para se referir ao Rio de Janeiro, a outras cidades modernizadas e até a cidades fictícias. Mesmo a crônica de Coelho Neto já havia circulado, embora a Cidade Maravilhosa não fosse identificada literalmente como o Rio de Janeiro. Sem dar a autoria à Jeane Catulle nem a Coelho Neto, o que talvez seja plausível é que o termo Cidade Maravilhosa já figurasse em conversas frívolas e/ou ilustradas e de modo sensível estava sendo incorporado e lapidado pela literatura. Enfim, abdicamos da tarefa de especificar uma origem ou autoria, mas localizamos o período de sua frequência. Factual, crítica, elogiosa, poética ou ficcional, as narrativas confluíram para um só movimento: o de dar legibilidade ao Rio de Janeiro como ambiente urbano e moderno.

Sem definir uma origem e autoria, nos resta elaborar proposições sobre o emprego do termo relacionado ao Rio de Janeiro nos questionando sobre sua adesão pela população. Optamos por uma compreensão do termo como uma representação social. Lapidando o conceito, a representação social se configura mais local e culturalmente, dando suporte para estudos comunicacionais. Se realizam nas relações mediadas pela linguagem, como fruto da união entre a cultura e a comunicação. A ocorrência se dá em um contexto social, determinado espaço temporal, e ganha impulso amparada por 
suportes técnicos. Conforme descreve Moscovici (1978), as representações sociais são "entidades quase tangíveis", um conjunto de conceitos, enunciados, afirmações ou explicações que surgem no cotidiano e se desenvolvem nas trocas, nas combinações interindividuais. Grosso modo, é o dizer sobre algo que adquire importância para uma dada coletividade. E por ser e estar para as interações e o coletivo, às representações sociais não cabem autoria ou propriedade, posto que são essencialmente susceptíveis de transformações na medida do compartilhamento.

E explorando a representação, pela noção de mediação e na potência do alastramento, em 1933 a emissora Mayrink Veiga pôs no ar o programa "Crônicas da Cidade Maravilhosa". Idealizado e locutado por Cesar Ladeira, nele eram lidos textos escritos por Genolino Amado (COSTA, 2001, p.143). O programa diário era um convite a tematizar sensivelmente a cidade a partir de crônicas literárias. E inspirado no título do programa de rádio, no carnaval de 1935, André Filho compõe a música Cidade Maravilhosa, gravada pelas irmãs Carmem e Aurora Miranda, para o Festival da Juventude. O lançamento da música ocorreu sem grande repercussão. E no carnaval do ano seguinte foi inscrita no Concurso de Carnaval da Prefeitura da Cidade do Rio de Janeiro, alcançando o segundo lugar. Na música a Cidade Maravilhosa é clamada repetidas vezes, cheia de encantos mil, como coração do Brasil, numa metáfora para a função de capital

\section{O Estado da Guanabara}

Na segunda imagem caleidoscópica do Rio de Janeiro a cidade perde a função de capital da república. No período cintilam incertezas quanto ao futuro da cidade com a transferência da capital para Brasília e a criação do Estado da Guanabara como um arranjo compensatório do ponto de vista político e econômico. Entram em cena narrativas sobre a Cidade Maravilhosa almejando forjar uma identidade local sem necessariamente se desfazer do prestígio de, por um longo período, ter exercido a capitalidade. No âmbito das disputas simbólicas, o planejamento urbano modernista passa a dar o tom do ressentimento político na confrontação com a nova capital, Brasília. E a cultura se faz arena performativa para a manutenção do Rio de Janeiro como a representação do país. 
Precisando, em 1960 o Rio de Janeiro deixa de ser a capital federal. Em acato a uma orientação constitucional de criação de um Distrito Federal, Brasília torna-se a nova capital. E a mudança, ainda que prevista desde a instauração da República, impacta sobreforma o Rio de Janeiro econômica, política e simbolicamente. Pelo viés da economia, as atividades produtivas desaceleraram, o mercado esfriou e o poder de arrecadação diminuiu. Do ponto de vista político, o deslocamento de figuras influentes culminou na falta de representação em favor da cidade na instância federal, configurando um projeto de equiparação do Rio de Janeiro a todo e qualquer outro município. E no plano simbólico, a cidade perde a grandiloquência ao ser destituída da missão de espelhar a grandeza da nação.

Visando abrandar os impactos da perda da função de capital, os políticos locais foram firmes e comprometidos em trabalhar por condições razoáveis para a transição institucional, conferindo à cidade algum amparo para preservar sua estrutura administrativa e reorientar a política econômica. E como resultado o Rio de Janeiro tornou-se Estado da Guanabara. Descrevendo a entidade política e juridicamente, o Rio de Janeiro estaria sob tutela federal, representado por uma bancada estadual, com uma administração municipal.

Remediadas as questões econômicas e políticas com a criação do Estado da Guanabara, a complicação recaiu na questão da autonomia e identidade do Rio de Janeiro. Exercendo a capitalidade desde 1763, como sede da colônia, passando pela corte e império, chegando à república na virada do século XIX para o XX, era inviável da noite ao dia apagar as marcas de um longo período. A cidade era instrumentalizada espacial, administrativa, política e simbolicamente para expressar um todo mais que a si. E ver-se obrigada a tornar-se uma unidade federativa igual à toda e qualquer outra se configurava em algo entre o desafio e o acinte. Todavia, a eficiência na produção e difusão cultural, ou mais objetivamente o fortalecimento da identidade da Guanabara, foi instrumentalizada para a preservação do prestígio do Rio de Janeiro no cenário nacional.

Seguindo a compreensão da produção do espaço como eixo articulador das relações de poder no sistema de acumulação capitalista, novamente o planejamento urbano é a medida da encenação do poder. Carlos Lacerda, primeiro governador eleito da Guanabara, contrata uma firma estrangeira para elaborar um plano urbanístico e sua decisão provoca protestos de diversos setores da sociedade, órgãos de classe, profissionais relacionados ao planejamento urbano e entusiastas do nacionalismo. 
Alegavam que a contratação de uma firma estrangeira era um disparate; afinal, não faltavam no país profissionais talentosos, capazes de elaborar um plano. Sem a objetiva intenção de afrontar ou desmerecer os profissionais brasileiros ou os entusiastas do nacionalismo, o que estava nos planos do governador era uma disputa narrativa com a nova capital, Brasília.

Brasília foi concebida como um símbolo grandioso de um Brasil novo, introduzindo em um espaço "sem história" um sentido discursivo, pela concepção arquitetônica e urbanística, que fazia brilhar o momento de impulso econômico e a confiança no desenvolvimentismo como caminho para o futuro. Na encenação do poder ao construir Brasília, diz Balandier (1982, p.11):

[...] uma capital nova materializa uma nova era; ela mostra os princípios de um empreendimento coletivo; é o espetáculo que o poder oferece da nação em atividade e dele próprio. Um decreto a cria, principalmente para lhe construir uma força expressiva. Brasília é a ilustração mais importante. A mais de mil quilômetros do litoral, onde se situam as cidades históricas, sobre um planalto de vegetação escassa, abandonado a rebanhos nômades, a capital federal do Brasil foi edificada em 4 anos.

Carlos Lacerda compreendeu a essência e os sentidos dos discursos na construção de Brasília e azeitou sua atuação para ingressar em uma disputa. Na emulação selecionou o urbanista Constantino Doxiádis, representante renomado de uma corrente crítica ao modernismo praticado em Brasília. Investiu no respaldo técnico e consistência teórica como providenciais para costurar ao menos dois objetivos. Um deles era o de manter a distinção, excelência e prestígio de um espaço que por tanto tempo exerceu a função de capital, fortalecendo a autoestima da população da carioca. E o outro, com uma dose considerável de vaidade, era o de preparar o terreno político para a sua candidatura à presidência.

Apesar do Estado da Guanabara ter assumido como desafio a organização da estrutura política e administrativa e a atualização da encenação do poder no planejamento urbano, a consolidação da nova fase institucional sui generis exigia também esforços no campo simbólico, buscando força e legitimidade pela identificação e adesão da população aos projetos de futuro, forjando a irmandade na ilusão da partilha de ideais. E caminhando pelo campo simbólico-cultural, o desenrolar dos fatos em torno da elaboração de uma discursividade grandiloquente, capaz de distinguir o Rio de Janeiro e encher de orgulho seus habitantes, dá nitidez às tensões entre os representantes 
políticos, que detêm a prerrogativa de produzir discursos oficiais, e atores diversos da sociedade, comprometidos com a defesa de expressões diversas às do poder instituído.

Ao mencionarmos as expressões distintas da atuação do poder público, damos visibilidade para novos atores políticos e simultaneamente revelamos a identidade local como uma questão, um problema instaurado pela transição institucional. O Estado da Guanabara nascia, por assim dizer, com a missão de recriar, atualizar os discursos sobre o lugar, tocando o sentimento de pertencimento, revigorando o imaginário local. Com Eni Orlandi (2002) tratamos dos expedientes da transição institucional como acontecimento discursivo, ou seja, o acontecimento que se "abre para uma nova discursividade, produz efeitos metafóricos que afetam a história, a sociedade e os sujeitos em muitas e variadas dimensões: política, cultural e moral" (ORLANDI, 2002, p.52).

Entre as ações de redefinição do imaginário e, em consequência, dos discursos sobre o local para nutrir o sentimento de pertencimento, a música Cidade Maravilhosa foi apropriada como uma narrativa da cidade, com o estatuto de marcha oficial. Fernando Krieger (2008), curador do acervo José Ramos Tinhorão, do Instituto Moreira Salles, produziu um texto que percorre a trajetória da música como representação oficial da cidade. E a partir da trajetória da música associada ao estado da Guanabara trazemos para a superfície os sentidos dos discursos acerca da Cidade Maravilhosa.

Segundo Krieger, Cidade Maravilhosa tornou-se a "marcha oficial da Cidade do Rio de Janeiro", através da Lei no 5, de 5 de maio de 1960, proposta pelo vereador Salles Neto e promulgada pelo governador Carlos Lacerda". No entanto, a população compreendeu a marcha como um hino. E o deslizamento tem uma proporção tão vultuosa que mesmo na atualidade é frequente nos depararmos com registros imprecisos, como ocorre com Santos (2015, p.134) ao discorrer sobre o hino oficial e não sobre a marcha oficial:

Entre os símbolos representativos do novo estado cabe ressaltar a definição do hino oficial. O vereador Francisco Sales Neto, da União Democrática Nacional (UDN), apresentou projeto sugerindo a escolha da marcha Cidade maravilhosa, de André Filho. O governador Sette Câmara o sancionou através da lei n. 5, de 25 de maio de 1960. Essa escolha não foi unânime, pois essa canção era considerada profana e excessivamente popular.

O que é importante darmos conta é que a partir desse deslizamento, de marcha para hino, se inicia a tentativa de controle do discurso de poder, ameaçando 
seguidamente o status da música como representação da cidade. As primeiras ofensivas tentavam esclarecer a confusão e recorriam à lei para distinguir hino de marcha oficial, conforme podemos observar em matéria publicada na Tribuna da Imprensa:

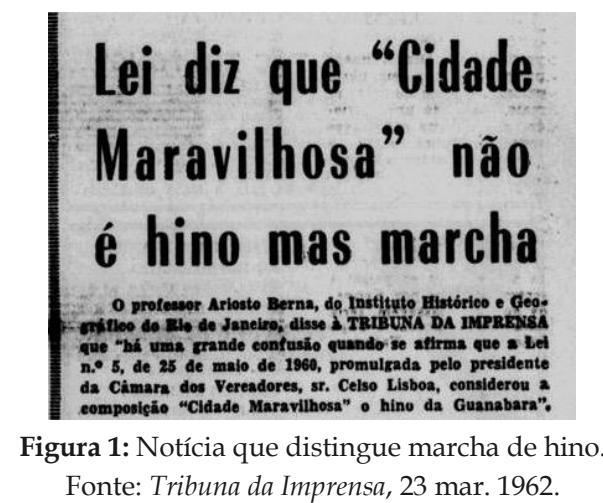

A rigor, um hino e uma marcha de carnaval, em estilo e função, guardam distinções. Os hinos se instituem entre os séculos XIX e XX, com a emergência de países independentes na Europa. Com estilo musical típico e tom solene, um hino tem como função política sintetizar a nação, forjando a união ao glorificar histórias e enaltecer a cultura. Já as marchas de carnaval, consagradas no Brasil mais expressivamente a partir de 1920, são inspiradas nas marchas populares portuguesas. Uma marcha carnavalesca tem tom popular, melodia simples, letras burlescas e a função de animar um período de festa do calendário cristão.

E usando como argumento a necessidade de um hino que refletisse tradicionalmente o sentimento patriótico dos cariocas, em 1962 a deputada Lygia Bessa Bastos encabeçou um movimento para a abertura de um concurso para a escolha de um novo hino. Alegava que a marcha Cidade Maravilhosa era inadequada para atos oficiais solenes. Contrários à argumentação da deputada, jornalistas, intelectuais e artistas engrossaram um coro em defesa da versão original da marcha Cidade Maravilhosa como hino da cidade. Entre as vozes mais destacadas estavam a do colunista Sérgio Cabral, o jornalista Prudente de Morais Neto, do maestro e compositor César Guerra-Peixe e do escritor Carlos Drummond de Andrade.

Em resposta às manifestações de artistas, intelectuais, jornalistas e, por extensão, da opinião pública, em 1965 o governador da Guanabara, Carlos Lacerda, adquiriu os direitos autorais da música que seguia como marcha oficial. 


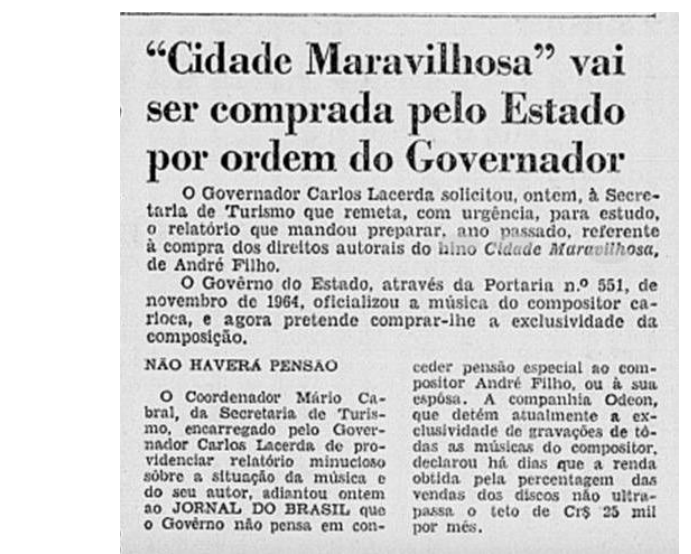

Figura 2: Notícia sobre a compra dos direitos autorais do hino. Fonte: Jornal do Brasil, 25 mar. 1965

O imbróglio parecia remediado com a compra dos direitos autorais, mas em 1967 o deputado Frederico Trotta trouxe de volta a demanda por um hino tradicional, encaminhando para a Assembleia Legislativa um Projeto de Lei que estabelecia a criação de um concurso para a escolha de um novo hino, em substituição à marcha "Cidade Maravilhosa".

Apesar das ofensivas, Cidade Maravilhosa resistiu, consagrando-se como hino da Guanabara. Permaneceu como um elemento ritualístico, executada em aberturas e encerramento de eventos oficiais, celebrações e festividades. E mesmo após a fusão da cidade do Rio de Janeiro como o estado do Rio de Janeiro a marcha não perdeu seu status. Em 2003 o prefeito Cesar Maia ratificou a canção como hino oficial do Rio de Janeiro. E em 22 de Maio de 2014, o Prefeito Eduardo Paes publicou no Diário Oficial um Decreto que determina que os alunos das escolas da rede municipal de ensino cantem o hino oficial da cidade, Cidade Maravilhosa, uma vez por semana.

Cumpre destacarmos a partir da trajetória da música Cidade Maravilhosa que o poder público tem a prerrogativa de produzir o discurso de poder, de dar o crivo de oficial. No entanto, não consegue atuar soberanamente na produção de sentidos. Não cabe portanto à produção de uma identidade a ideia de algo planejado, instituído e acabado, mas sim de um processo, de uma permanente negociação, de um campo de disputas.

Sobre a cultura como eixo para atuação política temos duas contribuições ricas que desembocam na noção de identidade. Benedict Andersen (2008) nos ilumina para a ideia de construção de comunidades, em analogia à nação, em uma trama que envolve instâncias culturais e políticas. Nos abre caminho para possibilidades de compreensão das produções simbólicas no limiar de uma interlocução, na qual a cultura exerce uma 
função centrípeta. Passando especificamente para os modos de abordar a cultura, aos estudos culturais, Hall (1997) nos propõe a concepção da cultura menos como objeto e mais como prática, produzindo os significados que viabilizam o social. Para o autor, a cultura:

[...] não pode mais ser estudada como uma variável sem importância, secundária e dependente em relação ao que faz o mundo mover-se; tem de ser vista como algo fundamental, constitutivo, determinando tanto a forma como o caráter deste movimento, bem como a sua vida interior (HALL, 1997, p. 06).

No processo de atualização dos discursos sobre o Rio de Janeiro, relacionado com a perda da capitalidade, temos como efeito mais imediato o deslocamento do nacional para o local. E como reflexo desse deslocamento, há uma profusão de discursos para dar conta de uma identidade, distinção com foco na partilha de experiências/afetos relacionados com a dimensão territorial. Os discursos sobre a cidade são redefinidos, rompendo com a história que garantia a permanência das coisas como eram e adesão a uma história capaz de sustentar, de dar significado, às mudanças que estão ocorrendo. E tomando o adágio de que uma mentira repetida à exaustão torna-se verdade, a Guanabara além de tecer discursos para se autoafirmar, se reconhecer como a Cidade Maravilhosa, em seus encantos mil conseguiu se expressar como "coração do meu Brasil", conforme o refrão do hino que muitos repetem mas nem todos percebem.

\section{O Rio de Janeiro pós-fusão}

A última imagem institucional do Rio de Janeiro é a mais ampla e complexa por alcançar a atualidade e estar em aberto. Embora haja um desenrolar de fatos importantes nos primeiros anos após a fusão da cidade com o Estado do Rio de Janeiro, como uma sucessão de gestões de prefeitos nomeados pelo governador, o início da escolha de prefeito por voto direto e a quebra da prefeitura, partiremos da sequência de doze anos de um projeto liberal encabeçado por Cesar Maia. Privilegiamos o Planejamento Estratégico como deflagrador de uma nova concepção urbana, incitando novas discursividades sobre a Cidade Maravilhosa.

A eleição de Cesar Maia em 1993 dá início a um novo ciclo na administração pública e na produção e gestão do espaço urbano, com uma orientação política à direita, retomando com novos propósitos a narrativa da administração eficiente e combate a 
vícios políticos. O que efetivamente consolidou uma nova fase do Planejamento Urbano na cidade é assinalado em um texto referência do sociólogo Carlos Vainer:

Em 22 de novembro de 1993, a Prefeitura do Rio de Janeiro firmava com a Associação Comercial (ACRJ) e a Federação das Indústrias (FIRJAN) um acordo para a promoção do Plano Estratégico da Cidade do Rio de Janeiro (PECRJ). Em 4 de fevereiro de 1994, 46 empresas e associações empresariais instauraram o Consórcio Mantenedor do PECRJ, garantindo recursos para o financiamento das atividades e, particularmente, para a contratação de uma empresa consultora catalã, de profissionais que iriam assumir a Direção Executiva do Plano e de outros consultores privados. Em 31 de outubro do mesmo ano, em sessão solene, era instalado o Conselho da Cidade - "instância maior do Plano Estratégico da Cidade do Rio de Janeiro", segundo os termos constantes do convite assinado triplicamente pelos presidentes da ACRJ, da FIRJAM e pelo prefeito (VAINER, 2000, p.105-106).

E por um período de doze anos, três cumprindo mandato como prefeito e um tendo à frente da prefeitura Luiz Paulo Conde, seu Secretário de Urbanismo, Cesar Maia orientou os rumos da cidade, conectando a gestão do espaço urbano às forças do mercado, abrindo caminho para projetos que mesclam a natureza e o interesse de entes públicos e privados, sob a prescrição liberal batizada de Plano Estratégico, que também atende pelo apelido de empreendedorismo urbano. Nesse fito, atenção e recursos foram canalizados para a construção e/ou readequação de equipamentos esportivos e estruturas para receber na cidade os Jogos Pan Americanos em 2007. O investimento era justificado pela controversa noção de legado. Seria como uma dádiva concedida à cidade e à população pela recepção do evento. No entanto, a dádiva era paga com recursos públicos e era tomada como prioridade frente às demandas mais básicas da população.

É mister notar que as estruturas para promover os Jogos Pan Americanos de 2007 funcionaram como um discurso, concreto e simbólico, para o êxito do evento, mas eram também o ensaio da cidade para alçar objetivos maiores. Serviu de baliza para a candidatura da cidade para sediar a Copa do Mundo em 2014 e as Olimpíadas de 2016. Nos discursos do poder público é detectável o empenho em forjar convenientemente a vocação da cidade: recepcionar grandes eventos. E também uma identidade para os cariocas, como extrovertidos e hospitaleiros.

O discurso da vocação da cidade e da identidade do carioca funcionam a partir do mecanismo de construção de falácia. Na falácia o enunciado é montado e verificável por uma lógica, sem contudo corresponder a uma sentença verdadeira. Sobre a sua vocação da cidade, conforme recepciona eventos, a cidade desenvolve experiência em recepcionar eventos. No entanto, não quer dizer que recepcionar eventos seja uma 
vocação. Talvez soasse mais honesto afirmar ser uma expertise. E sobre o ser extrovertido e hospitaleiro, há uma generalização, uma homogeneização que tem por trás o objetivo de que o carioca acredite e invista nessas qualidades.

Retomando a ordem mundial se assentando no Rio de Janeiro, a fluidez passa a informar o comportamento dos grandes capitais, barganhando entre as cidades mundiais as melhores condições para a maior rentabilidade. E de modo análogo atinge as relações de trabalho, relações sociais, políticas e, por extensão, as inscrições e atuações dos sujeitos. No Rio de Janeiro, o planejamento centralizador, tecnocrático, que informava um projeto político e econômico nacional desenvolvimentista, se converte no planejamento estratégico, com foco local, alinhado a uma gramática empresarial[7]. A cidade atua como uma empresa e o planejamento se expressa como estratégico. Volta-se para áreas pontuais, delimitadas e com a intervenção como uma prescrição para resolução de problemas, com planos reproduzíveis, executados sob rigoroso controle de tempo e recursos, com etapas definidas e resultados avaliáveis. As cidades passam a ser estruturadas e geridas em uma perspectiva concorrencial internacional, cujo objetivo é a atração de grandes capitais, seja de investidores ávidos por vantagens, seja do mercado do turismo, especialmente o impulsionado pela produção de mega eventos. Com efeito, a identidade da cidade torna-se uma marca, o planejamento uma gestão, as políticas não muito mais que ações publicitárias (por se inclinarem mais ao mercado que à cidadania), a população um conjunto de atores articuláveis e a cidade em si uma mercadoria.

O que a atual imagem institucional traz como novidade é a argúcia do poder público em conduzir a discursividade sobre a cidade em duas frentes: a local e a global. $\mathrm{Na}$ primeira, apaziguando conflitos e inflando egos em torno do pertencimento/identidade para garantir a execução de projetos afinados a objetivos políticos e econômicos. Na segunda, fazendo o canto da sereia, atraindo grandes capitais com incentivos diversos, desde as isenções fiscais até a flexibilização de regras à conveniência do empresariado, além do fomento ao turismo com promessas de experiências.

A atuação da sociedade civil como produtora de narrativas no período pós-fusão é ampliada, sobretudo por conta de dois fatores. O primeiro deles é a Constituição de 1988, que abriu caminhos para a maior participação política da sociedade, juntamente com a maior autonomia dos municípios. Soma-se ao ideal de participação política o desenvolvimento das tecnologias de comunicação, o segundo fator. O barateamento dos 
equipamentos de gravação e edição de som e imagem e o acesso à internet promoverão uma transformação sem par na comunicação.

No que tange à função de emissor e receptor, o período testemunha a mudança paradigmática da comunicação de poucos emissores direcionada a muitos receptores para a comunicação de todos para todos. O que observamos na mediação e alastramento de conteúdos agora apreendemos na simultaneidade de emissões e potente equiparação de emissores. Qualquer conteúdo comunicacional que anteriormente poderia ser preterido, estar diluído ou contido em opiniões, gostos pessoais ou ideias do senso comum, com o uso de equipamentos eletrônicos ligados à internet alça a potência de atingir um público numericamente expressivo e influenciar a opinião pública. O que na produção de narrativas sobre a cidade provocará ruídos, incomodando as coalisões de poder por trás das narrativas oficiais.

Na relação entre o local e o global assinalamos como fenômeno disseminador de discursos sobre o lugar o planejamento estratégico, as operações urbanas consorciadas. Como um projeto reproduzível, iniciam com o diagnóstico de degradação urbana, estagnação econômica e risco social em áreas específicas da cidade. Na sequência, fornecem como solução a revitalização na forma de uma parceria da iniciativa pública e entes privados, exibindo a preocupação econômica, social e até ambiental com o local e encobrindo a alavancagem dos grandes capitais desenraizados, sobretudo os ligados ao setor imobiliário.

No Rio de Janeiro, a primeira operação urbana consorciada foi o Projeto Porto Maravilha. O nome do projeto não à toa se vale da narrativa da Cidade Maravilhosa. Os portos foram e continuam sendo a metáfora do liminaridade entre a cidade e o mundo, referência para a entrada e saída de pessoas, mercadorias e ideias. Quando o projeto incorpora o termo "Maravilha" para dar nome ao porto temos uma espécie de retorno do motivo edênico (CARVALHO, 1998), do imaginário fantasioso dos navegantes ao chegarem às Américas (GIUCCI, 1992). No entanto, em uma simbologia renovada, não mais flertando com o distante e desconhecido, mas com o próximo e o futuro, conforme podemos intuir ao tomarmos a mais eloquente atração do projeto, o Museu do Amanhã. Trata-se de uma arquitetura de impacto e monumentalidade, projetado para ser uma experiência de arrebatamento, na pegada de uma economia das experiências nas cidades mundiais, cujo ideal seria o de produzir nos atos cotidianos o singular e memorável (PEIXOTO, 2012). 
Um outro desdobramento da proliferação de discursos em par com a Cidade Maravilhosa foram os expedientes em torno da comemoração dos 450 anos do Rio de Janeiro, intimamente ligado com a expansão de um mercado de bens culturais. Buscaremos retratar a vigilância comemorativa captando as narrativas sobre a Cidade Maravilhosa e/ou hábitos e estilo dos cariocas produzidas pelo poder público.

Tomamos o uso do ideário da Cidade Maravilhosa no Projeto da Prefeitura do Rio de Janeiro, na gestão do Prefeito Eduardo Paes, para comemoração dos 450 anos da cidade. Na condição de produtor de um discurso oficial da cidade, a prefeitura faz uso consciente e consistente da prerrogativa de selecionar o que deve ser lembrado, e o que convém ser esquecido. O projeto se enquadra na perspectiva ritualística de preservação da memória, numa ação orientada que opera no tempo kairós, do mito e do rito, o tempo da oportunidade, em detrimento do tempo kronos, newtoniano, linear, uniforme e quantificável. A ação é de extrema argúcia e profundo conhecimento, pois afina com o título de Cidade Maravilhosa ${ }^{[8]}$ uma promessa de experiência da cidade para o mundo e a de identidade para a população local, exaltando virtudes e encobrindo vicissitudes.

A prefeitura investiu na iniciativa de celebrar os 450 anos da cidade, ciente de que espontaneamente a data não é lembrada, a cidade, sua história e os simbolismo perdem força. Como símbolo para a comemoração, produziu uma imagem que utiliza os números 4, 5 e 0 para compor uma expressão de satisfação. Para divulgação do projeto, desenvolveu uma home page que disponibilizava, entre outras informações, um link chamado Marca. E nele uma explicação do que é a marca, como foi elaborada, o que significa e um manual de como deve ser usada. Na explicação diz:

[...] é uma expressão que, além da cara do carioca, é a cara da comemoração dessa festa. Uma proposta para provocar reflexões lúdicas sobre quem somos e o quanto amamos estar onde estamos. Ela foi pensada para resgatar o orgulho de pertencer, através de uma ideia simples e direta: se o carioca é multicultural, multiétnico e multifacetado, a marca deve espelhar tudo isso. ${ }^{[9]}$

Na sugestão das reflexões lúdicas, a questão do pertencimento é uma importante chave de interpretação da atualidade. Em termos sociológicos, Bauman (2006, p. 5-9) aborda as reações dos indivíduos às inconstâncias da atualidade, abordando as crises de pertencimento. Considera que em virtude das inconstâncias, construímos e sustentamos referências para nossas identidades em trânsito, na tentativa de pertencer, no afã do conforto e segurança. No caso apresentado da comemoração dos 450 anos do Rio de 
Janeiro, a prefeitura trabalha com estoques de referências e memória capazes de forjar uma identidade, simulando a sensação de pertencimento.

E na concepção de uma identidade, irmanando, forjando a sensação de pertencimento, a narrativa da prefeitura se abriu para a irreverência, ao gosto pela paródia, fazendo a representação da cidade e do carioca prevendo a criatividade e reação da população aos discursos do poder. Reforçando o que já assinalamos, nos vale menos a identificação de quem produz o discurso e mais a perspectiva da dinâmica, da negociação, das disputas em torno da produção dos sentidos.

\section{Considerações finais}

Nos dedicamos aos discursos sobre o Rio de Janeiro inspirados no termo "Cidade Maravilhosa". Conjunturalmente sensível, a Cidade Maravilhosa é tomada como um difusor de discursos sobre o Rio de Janeiro, articulando o imaginário, a identidade do lugar e de seus habitantes, vezes diluído nos ideais e formas do planejamento urbano, vezes decantada na seara cultural. Em ambos os casos, performando disputas políticas.

Analisamos o "algo a mais" nos discursos que, conforme assinala Foucault, funcionam de modo a fazer com que o poder seja aceito. E mais do que aceito, que o poder seja naturalizado, ou, se percebido, compreendido como necessário. Em tal perspectiva, o ritual, a encenação do poder inspirado na Cidade Maravilhosa, cumpre devidamente sua função de encantar, de se valer de uma simbologia para forjar a crença no perfeito andamento da sociedade. Afinal, o erro fatal no exercício do poder seria deixar saltar aos olhos da população a famigerada realidade do Rio de Janeiro.

O discurso da Cidade Maravilha encanta o mundo e localmente tem como efeito o bom aproveitamento político. Seu brilho é tão intenso que quase cega a percepção nua e crua das experiências na cidade. De modo amplo seduz e inebria, com promessas de experiências. Mas na população local produz um embotando da cidadania e, em algum grau, da agência política. Afinal, a cidade se defronta com problemas, desde os típicos das grandes cidades como o saneamento, a poluição visual e sonora, o trânsito caótico e o déficit habitacional, até questões um tanto mais peculiares como as favelas enquanto solução precária das camadas desfavorecidas para o acesso à habitação no solo urbano, a violência descontrolada em áreas específicas, a destinação desigual de cuidados e recursos entre os bairros para o desenvolvimento e a gestão urbana e o sistema de transporte coletivo mais informado pelos interesses de grandes empresários que pelas 
demandas de mobilidade da população. A tudo isso a metonímia “Cidade Maravilhosa" resiste e tudo isso ela reveste.

\section{Notas de rodapé}

[1] Consideramos os trabalhos desenvolvidos na França, a partir da segunda metade da década de 1960, tendo Michel Pêcheux como referência articuladora. Cabe destacar que embora a nomenclatura "Análise de Discurso Francesa" sugira uma homogeneidade, especialmente quando mencionada como escola, há no movimento contribuições com questões, conceitos e referências diversas, ainda que confluam e se caracterizem pela problematização da linguagem incorporando as exterioridades.

[2] Experiências metodológicas para a compreensão da complexidade da cidade contemporânea (FAPESB/CNPq - PRONEM - Programa de Apoio a Núcleos Emergentes) é um projeto cuja proposta é investigar metodologias de apreensão da complexidade das cidades, articulando três linhas de abordagem que costumam ser tratadas separadamente: historiografia, apreensão crítica e experiência estética-corporal. A pesquisa toma a noção de experiência e de sua transmissão em forma narrativa, como princípio norteador da investigação metodológica. Organizado pela Prof. Paola Berenstein, do PPG-AU/FAUFBA, em colaboração com pesquisadores da UNEB e convidados, o projeto dividido em quatro tomos reformula teorias, abordagens e práticas do planejamento urbano e do urbanismo, propondo discussões sobre os limites de suas ferramentas mais tradicionais de apreensão e compreensão da cidade, particularmente no contexto da complexidade de cidade contemporânea. Sobre a proposta de investigação, Paola Berenstein discorre: "Para articular memória, narração e história, propomos usar a ideia de montagem urbana como forma de conhecimento da cidade e do Urbanismo. Partiremos de um tipo específico de montagem, uma forma singular de pensar por montagens, por deslocações, decomposições e outras disposições, ao buscar apreender, de forma caleidoscópica - forma privilegiada da modernidade - essa 'desordem do mundo'" (JACQUES, 2015, p. 47).

[3] A obra faz parte da Coleção Metrópoles, da Editora Record. O autor, convidado a falar sobre sua cidade, examina o Rio de Janeiro como lugar, memória, representação, sonho e projeto global no imaginário nacional e local. Trata-se de uma publicação que mescla, sem assumir metodologicamente, as noções de história e memória. Grosso modo, a primeira seria uma narrativa do passado balizada institucionalmente, e a segunda uma narrativa do passado em diálogo com afetos e as necessidades do presente. Para uma compreensão mais aprofundada sobre história e memória, que por seu turno norteará nossa reflexão, ver Nora (1981), Halbwachs (2006) e Pollak (1989).

[4] Em uma tradução nada rigorosa, sobretudo por conta do teor poético e expressões da época, é notável o rasgado elogio em êxtase com a cidade, destacando elementos da natureza: Nunca tanto esplendor deslumbrou os olhos! / Esta é a terra de toda a luz, / Esta é a terra da beleza plenária / Belezas terrestres e belezas do céu.

[5] Coelho Neto publicou o "artigo 'Os sertanejos', na página 03, do jornal 'A Notícia', edição de 29.11.1908” (CAMPOS, 1965, p. 76). A informação circula e chegou a ser usada na página pessoal do prefeito Eduardo Paes até 2014. No entanto, a página e seu conteúdo foram retirados do ar. Embora seja possível ver um link com a informação em um profile em homenagem a Coelho Neto no Facebook em https:/ / www.facebook.com/familiacoelhonetto/ (acessado em 17 de Setembro de 2016), na postagem cujo título é "Há 105 anos, Rio era chamado de Cidade Maravilhosa pela $1^{a}$ vez / Eduardo Paes, prefeito do Rio".

[6] O embaralhamento entre o conteúdo de uma produção literária e a representação de um lugar é um fenômeno curioso, mas nem por isso inédito. Só para citar, temos a famosa associação entre o romance A Moreninha, de Joaquim Manuel de Macedo, e Paquetá. Um dos cenários do romance 
é uma fazenda/ilha, em que jovens se encontram e se enamoram. Esse local descrito no romance foi e é associada a Paquetá, apesar de em trecho algum do livro Paquetá ser citada.

[7] Carlos Vainer organiza um debate intelectual e político sobre a escala de poder local, dando conta das atuações dos governos municipais em uma conjuntura de redefinição da economia global. As cidades são incitadas a se engajar na economia global. Para tal, devem demonstrar capacidade estratégica empresarial para cumprir suas funções de modo vantajoso. Conferir em Vainer (2002).

[8] Além de Cidade Maravilhosa, o Rio de Janeiro o Rio coleciona outros título como o de Cidade Mais Feliz do Mundo, em pesquisa publicada pela revista Forbes, em 2009; Melhor Destino Gay Global, eleito pelo canal Logo, da MTV dos EUA, em 2009; primeira cidade do mundo a receber da UNESCO o título de Patrimônio Mundial como Paisagem Cultural Urbana, em 2012, e, mais recentemente, o prêmio de World Smart City 2013.

[9] Conferir em: <http://www.rio450anos.com.br/conheca-a-marca/>. Acesso em 19 de setembro de 2014.

\section{Referências}

ARANTES, Otília; VAINER, Carlos; MARICATO, Ermínia. A cidade do pensamento único. Petrópolis: Ed. Vozes, 2000.

BALANDIER, Georges. O poder em cena. Brasília, Universidade de Brasília, 1982.

CAMPOS, A. da Costa S. Dicionário de curiosidades do Rio de Janeiro. São Paulo: c Comércio e Importação de Livros, 1965.

CARNOY, Martin. Estado e teoria política. Campinas, SP: Ed. Papirus, 1988.

CARVALHO, José Murilo de. O motivo edênico no imaginário social brasileiro. Revista Brasileira de Ciências Sociais, São Paulo, v. 13, n. 38, p., out. 1998. Disponível em: <http://www.scielo.br/scielo.php?script=sci_arttext\&pid=S0102$69091998000300004 \& \operatorname{lng}=\mathrm{en} \& \mathrm{nrm}=\mathrm{iso}>$. Acessado em agosto de 2017.

FOUCAULT, M. Como se exerce o poder? In: DREYFUS, H.; RABINOW, P. Michel Foucault, uma trajetória filosófica. Rio de Janeiro: Forense Universitária, 1995.

A arqueologia do saber. Rio de Janeiro: Forense Universitária, 1997.

. Sobre a história da sexualidade. In: Microfísica do poder. Organização e tradução de Roberto Machado. Rio de Janeiro: Edições Graal, 2001. p. 243-276.

GIUCCI, Guilhermo. Viajantes do Maravilhoso: O novo mundo. São Paulo, Companhia das Letras, 1992.

HALBWACHS, M. A memória coletiva. São Paulo: Ed. Centauro, 2006.

HALL, Stuart. A centralidade da cultura: notas sobre as revoluções culturais do nosso tempo. In: Educação \& Realidade, Porto Alegre, v. 22, n.2, p. 15-46, jul./ dez, 1997.

JACQUES, Paola Berenstein. Montagem urbana: uma forma de conhecimento das cidades e do urbanismo. In: JACQUES, Paola Berenstein, BRITTO, Fabiana; 
DRUMMOND Washington (Orgs.). Experiências metodológicas para a compreensão da complexidade da cidade contemporânea. Salvador, EDUFBA, 2015. 4 v.

KRIEGER, Fernando. "Cidade Maravilhosa" I: André Filho e a saga de uma marchahino. In: Notícias do Acervo, IMS, 20 de Janeiro de 2015. Disponível em: <http://www.ims.com.br/ims/explore/acervo/noticias/cidade-maravilhosa-andrefilho-e-a-saga-de-uma-marcha-hino>. Acessado em agosto de 2017.

NORA, P. Entre memória e história: a problemática dos lugares. Projeto História: Revista do Programa de Estudos Pós-Graduados em História e do Departamento de História da PUC-SP, São Paulo, dez. 1993, p. 7-28.

MOSCOVICI, Serge. A representação social: Um conceito perdido. In: A representação social da psicanálise. Rio de Janeiro: Zahar, 1978, p. 41-81.

ORLANDI, Eni. Língua e acontecimento linguístico: para uma história das ideias do Brasil. São Paulo, Ed. Cortez, 2002.

Análise de discurso: princípios e procedimentos. Campinas, São Paulo, Ed. Pontes, 2007.

. Discurso fundador: a formação do país e a construção da identidade nacional. Campinas: Ed. Pontes, 2001.

PÊCHEUX, M. Semântica e discurso: uma crítica à afirmação do óbvio. 4. ed. Campinas: Pontes, 2009.

Análise de Discurso: Michel Pêcheux. Textos escolhidos por Eni Puccinelli Orlandi. Campinas: Pontes, 2011.

PEIXOTO, Paulo. Desafios à cultura urbana no contexto da economia das experiências e das narrativas interativas. Centro de Estudos Sociais, Universidade de Coimbra, 2012.

POLLAK, Michael. Memória, esquecimento, silêncio. Estudos Históricos, Rio de Janeiro, vol.2, n. 3, 1989.

SANTOS, Vicente Saul Moreira dos. A cidade do Rio de Janeiro no IV Centenário em algumas páginas literárias. Revista do Acervo, Rio de Janeiro, v. 28, n. 1, p. 132-143, jan./jun. 2015.

VAINER, Carlos Bernardo. As escalas do poder e o poder das escalas: o que pode o poder local? In: Cadernos IPPUR. Ano XV, n. 2, ago.-dez. 2001 / Ano XVI, n. 1, jan-jul. 2002, p. 13-32.

Os liberais também fazem planejamento urbano? Glosas ao Plano Estratégico da cidade do Rio de Janeiro. In: ARANTES, Otília; VAINER, Carlos; MARICATO, Ermínia. A cidade do pensamento único. Petrópolis: Ed. Vozes, 2000. p. 105-120.

Recebido em 17/07/2017

Aceito em 01/10/2017. 